Research Article

\title{
Investigation of Anti-MRSA and Anticancer Activity of Eco-Friendly Synthesized Silver Nanoparticles from Palm Dates Extract
}

\author{
Mohammed Jabber Al-Awady ${ }^{1}$, Asim Alaa Balakit ${ }^{2}$, Sharafaldin Al-Musawi ${ }^{1}$, Mohammed Jassim \\ Alsultani $^{3}$, Ahmed Kamil², Muntadher Alabbasi ${ }^{2}$ \\ ${ }^{1}$ Department of Genetic Engineering, Faculty of Biotechnology, Al Qasim Green University, Babylon, Iraq. \\ ${ }^{2}$ Department of Phrmaceutical Chemistry, College of Pharmacy, Babylon University, Babylon, Iraq. \\ ${ }^{3}$ Department of Physics, College of Science, Babylon University, Babylon, Iraq. \\ —Corresponding author. E-mail: mjk.chem@gmail.com; M.Awady@biotech.uoqasim.edu.iq
}

Received: Dec. II, 2018; Accepted: Apr. 30, 2019; Published: May 10, 2019.

Citation: Mohammed Jabber Al-Awady, Asim Alaa Balakit, Sharafaldin Al-Musawi, Mohammed Jassim Alsultani, Ahmed Kamil, and Muntadher Alabbasi, Investigation of Anti-MRSA and Anticancer Activity of Eco-Friendly Synthesized Silver Nanoparticles from Palm Dates Extract. Nano Biomed. Eng., 2019, I I (2): I57-I69.

DOI: 10.5101/nbe.v11i2.p157-169.

\begin{abstract}
In the present work, we investigated novel, green, and facile approach for the synthesis of stable silver nanoparticles by use of inexpensive and available Iraqi Zahdi palm dates extract as reducing and stabilizing agents. The formation and color change of dark brown suspension of silver nanoparticles were monitored and examined by ultraviolet-visible spectrophotometric analysis at maximum wavelength of $401 \mathrm{~nm}$. The produced nanoparticles were characterized by dynamic light scattering (DLS), Fourier transform-infrared spectrometry (FTIR), atomic force microscope (AFM), X-ray diffraction (XRD) and scanning electron microscopy (SEM)-energy dispersive spectroscopy (EDS). The results demonstrated that particle size distribution was around $90 \pm 40 \mathrm{~nm}$ which was in line with grain size of the nanoparticles measured by AFM, while the crystallite size was about $20 \mathrm{~nm}$ according to the results observed from XRD technique. Additionally, the zeta potential of synthesized silver nanoparticles was found to be nearly about $-25 \mathrm{mV}$, whereby the suspension showed high stability upon storing the sample in a cool place for a long period of time. The synthesized silver nanoparticles exhibited efficient antibacterial activity against pathogenic methicillin-resistant Staphylococcus aureus (MRSA) bacteria. They also showed enhanced anticancer activity against breast cancer cells (MCF7) with high apoptotic effect as compared with normal MCF10A cells, which confirmed the biocompatible nature of green synthesized silver nanoparticles. It is considered that nanosilver particles synthesized with palm dates extract may basically establish a significant step to synthesize such nanoparticles for topical applications as well as an alternative anticancer drug of existing chemotherapeutics of cancer.
\end{abstract}

Keywords: Green synthesis; Silver nanoparticles; Palm dates extract; Antimicrobial activity; Anticancer activity

\section{Introduction}

In the recent years, metal based nanotechnology has rapidly been developed due to their excellent unique chemical and physical properties, for instance, optical, electrical, antimicrobial, catalytic, magnetic and other properties, which are completely different from bulk materials of the same chemical composition (1-3]. 
The chemical composition on the particle surface, particle size, and surface charge has significant effects on the behavior of nanoparticles (NPs) [4-7]. Several chemical and physical methods were utilized to synthesize metal NPs, such as chemical reduction [8], electrochemical reduction [9], heat evaporation [10] and microwave irradiation [11]. However, these methods were used to avoid the agglomeration of NPs using surface passivators. The precursors used in the synthesis of NPs are having toxic nature which can profoundly contaminate the environment [12]. Also, the utilization of severe organic solvents/ surfactants [13] and strong reducing agents (e.g., borohydride or hydrazine) [14] usually produce large amounts of hazardous waste. In addition to that, some chemical species may be adsorbed on the surface of the chemically synthesized NPs, which can cause undesired effects in its applications [12]. Therefore, It is not possible to completely separate the toxic effect of silver NPs and silver ions. However, Das et al. have demonstrated recently to prevent the formation of $\mathrm{Ag}^{+}$ ions using nanotechnology combining with silica and proteins, and thereby reduction of toxicity [15]. It also turns out that metals migration from NPs can be easily stopped by coating or packing metallic NPs in organic or inorganic matrix like polymers, polyphenols, ceramics or glasses to be utilized for biomedical applications [16-18]. Hence, it is crucial and valuable in the field of nanotechnology to produce and develop greener, consistent, low cost, non-toxic and ecofriendly methods for the synthesis of NPs $[19,12]$.

Silver NPs are widely used nowadays, as it is one of the most significant noble metals. Such NPs were used as antibacterial agents and for some therapeutic uses [20]. They also play an important role in the pharmaceutical industry such as in the field of nanomedicine. Silver NPs have been acted as topical antibacterial agents for the treatment of bacterial skin infections [21, 22] as well as their potential role as anticancer agent in drug delivery where they efficiently enhance specific killing of cancer cells [23]. For instance, Piper nigrum-extract-synthesized silver NPs were utilized for investigating in vitro cytotoxicity action towards MCF-7 and HEP-2 cells. They revealed a substantial anticancer activity upon incubation with both MCF-7 and Hep-2 cells in comparison with Piper nigrum extract [24]. The synthesis of silver NPs can be conducted by various methods. The most popular procedure for the synthesis of silver NPs is chemical reduction using sodium borohydride $\left(\mathrm{NaBH}_{4}\right)$ since this route has limitations as mentioned above. Therefore, researchers have suggested utilization of green synthesis [25, 26] or biosynthesis [27] of silver NPs rather than sodium borohydride. This is due to the fact that the crude plant extract has specific metabolites such as phenolic acid, flavonoids, alkaloids and terpenoids, these compounds act as reducing agents on the one hand, and support the antimicrobial action on the other. These metabolites are responsible for the reduction of silver ion into nano sized silver which is environmentally friendly nano-sized silver particle using bottom-up technique [26, 28].

In this research, we demonstrated a greener synthesis of silver NPs through investigating the use of palm dates extract which is spreadable and available in the Middle East area, especially in the center and south of Iraq, as reducing and capping agents to synthesize ecofriendly silver NPs. The factors affecting silver NPs synthesis including temperature, extract volume, silver ion volume and its concentration, and time of heating were studied. The synthesized products were also characterized by ultraviolet-visible spectrophotometry (UV-Vis), Fourier transform-infrared spectrometry (FTIR), dynamic light scattering (DLS), X-ray diffraction (XRD), atomic force microscope (AFM) and scanning electron microscope (SEM). Additionally, the antimicrobial activities were examined and reported along with these characteristics, against the group of methicillin-resistant Staphylococcus aurous (MRSA) bacteria. The green synthesized silver NPs were also examined against cancerous cells such as breast cancer cell lines, as well as its apoptosis assay using flow cytometry.

\section{Experimental Section Materials}

Deionized water was used throughout this work which was purified by reverse osmosis and ion exchange system. Silver nitrate $\left(\mathrm{AgNO}_{3}\right)$ (ACS reagent, Purity $\geq 99.0 \%$ ) was supplied by Sigma Aldrich, Germany. Zahdi palm dates were purchased from local market in Babylon province in the center of Iraq. Molar-Hinton broth was obtained from szHiMedia Laboratories, India. Dialysis tubes (MWCO $12 \mathrm{kDa}$ ) with enclosures were purchased from SigmaAldrich, Germany. Ten pathologic bacterial isolates (Aeromonas hydrophil, Escherichia coli, Enterococcus faecali, Klebsiella pneumonia, Morganella morganii, Pseudomonas aeroginosa, Serratia marcescens, 
Staphylococcus aureus, Staphylococcus epidermidis, and Vebrio fluvialis) were provided by Biology Department, University of Babylon, Babylon, Iraq.

\section{Preparation of palm dates extract}

The extraction of Zahdi palm dates extract was prepared according to the procedure described in the reference with some modifications [29]. Briefly, the palm dates material (flesh) was washed and cleaned with deionized water, and then air dried at $20-25^{\circ} \mathrm{C}$ for $24 \mathrm{~h}$. The dried flesh was cut off into small pieces after taking the seeds off to obtain crude palm dates. The palm dates extract was prepared by soaking 25 $\mathrm{g}$ of the crude material into $150 \mathrm{~mL}$ deionized water and warmed up to $70{ }^{\circ} \mathrm{C}$ for $2 \mathrm{~h}$. The extract produced was filtered on Whatmann filter paper No. 1 and concentrated using a vacuum evaporator at $40^{\circ} \mathrm{C}$. The palm dates extract was maintained in the dark in a cool and dry place to be used later on. This extract should be freshly prepared immediately prior to each experiment of the synthesis of silver NPs in order to avoid any microbial contamination. Fig. 1 depicts colorful scheme for the synthesis of silver NPs using Iraqi Zahdi dates extract.

\section{Synthesis of silver nanoparticles}

3 mLof freshly prepared palm dates extract was placed in $10 \mathrm{~mL}$ white cap plastic tube. Then, $2 \mathrm{~mL}$ of $0.1 \mathrm{M}$ silver nitrate solution was mixed with the extract solution at room temperature. This mixture was diluted to $10 \mathrm{~mL}$ with deionized water and heated to 90 ${ }^{\circ} \mathrm{C}$ with continuous stirring for $15 \mathrm{~min}$. A dark brown suspension was formed which was then centrifuged for $15 \mathrm{~min}$ at $6000 \mathrm{rpm}$ to get rid of generated precipitates. The supernatant solution was dialyzed against $500 \mathrm{~mL}$ distilled water using $12 \mathrm{kDa}$ MWCO dialysis bag for $48 \mathrm{~h}$ with gentle stirring (distilled water was changed every $24 \mathrm{~h}$ ). Aliquots were taken at different reaction time to monitor the formation of silver NPs.

\section{Characterization of silver nanoparticles}

The formation of silver NPs was monitored using 1800-Shimadzu UV-visible spectrophotometer (Shimadzu, Osaka, Japan) in the wavelength range from $300 \mathrm{~nm}$ to $500 \mathrm{~nm}$. Deionized water was used as a blank for background correction of UV-Vis spectrum. FTIR analysis was carried out by using Bruker Fourier transform infrared spectrometer for the wave numbers ranged from $500 \mathrm{~cm}^{-1}$ to $4000 \mathrm{~cm}^{-1}$ which was used to investigate the existence of functional groups such as carbonyl, amines, or hydroxyl groups on the surface of nanoparticle. The particle size distribution and zeta potential were measured by Malvern Zetasizer Nano ZS (Malvern, UK) at $25{ }^{\circ} \mathrm{C}$ with an incident wavelength of $633 \mathrm{~nm}$ and a $173^{\circ}$ backscattering angle. The viscosity, refractive index, and absorption values of water and silver nanoparticles used in the Malvern software were $(\mu=0.8872 \mathrm{cP}, \mathrm{RI}=1.333)$ and $(\mathrm{RI}$ $=0.135$, absorption $=3.99$ ), respectively. Scanning electron microscope was supplied by FEI Quanta 450 SEM, Netherlands which was used for the studying the morphological nature of silver nanoparticles. Samples were mounted to be thin filmed on a carbon coated grid to increase the contrast of the SEM image and the

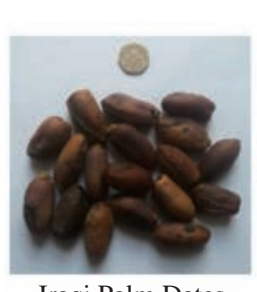

Iraqi Palm Dates

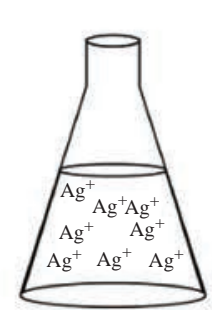

Silver Ion Precursor

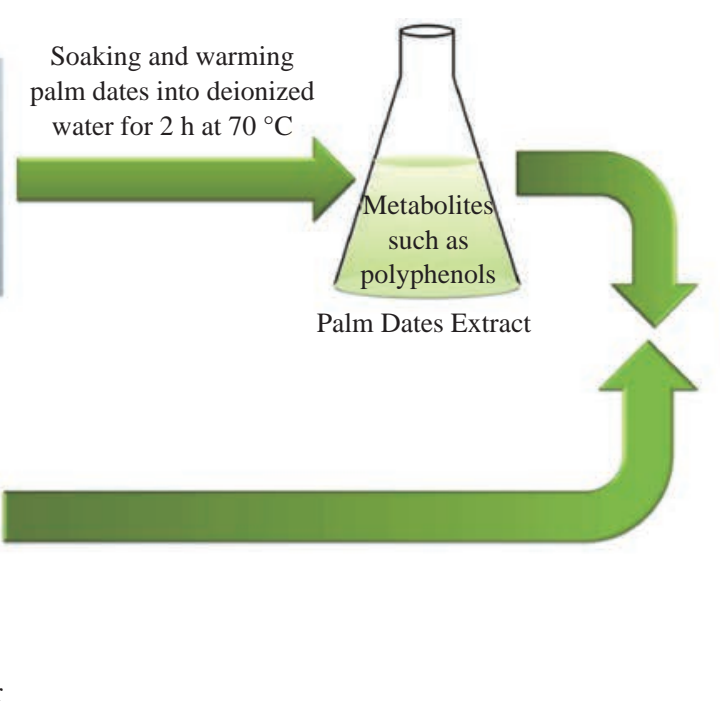

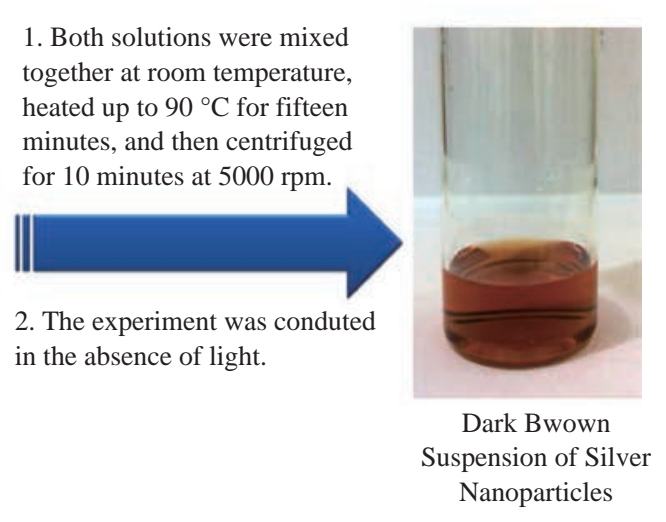

1. Both solutions were mixed together at room temperature, heated up to $90^{\circ} \mathrm{C}$ for fifteen minutes, and then centrifuged for 10 minutes at $5000 \mathrm{rpm}$.

Fig. 1 The colourful schematic for the synthesis of silver NPs using metabolites from Zahdi palm dates extract. 
elemental analyses were made using energy dispersive $\mathrm{X}$-ray analysis (EDXA). The crystallite size of the synthesized nanoparticles was also conducted by X-ray Diffraction (XRD) and atomic force microscope (AFM) through dispersing of silver nanoparticles liquid sample on a glass substrate using drop cast technique and evaporating of nanoparticles solvent before analysis. The morphological and structural study of synthesized silver nanoparticle was determined using (Carl Zeiss AG-Zeiss EM900, Germany) transmission electron microscope (TEM) setting at an acceleration voltage of $50 \mathrm{KeV} .25 \mu \mathrm{L}$ of prepared silver NPs suspension after sonication $(250 \mu \mathrm{g} / \mathrm{mL}, 60 \mathrm{~s}$ sonication) was dropped on 200 mesh formvar-coated copper TEM grid (grid size: $97 \mu \mathrm{m}$ ) without any staining. The grid was then rinsed with distilled deionized water (DDW) and dried in a vacuum desiccator until prepared for imaging.

\section{Antibacterial activity}

10 pathologic bacterial isolates (provided by College of Pharmacy / University of Babylon, Babylon, Iraq) were exploited to determine the minimum inhibitory concentration (MIC) value of the synthesized silver NPs. For this purpose the macro-dilution method according to Andrews [30] was employed. The inoculation solution was prepared by diluting the active growth of each bacterial isolate by normal saline to produce a suspension of 0.1 absorbance unit at 600 $\mathrm{nm}$. Then, the suspension diluted to 1000 times by Molar-Hinton broth (HiMedia Laboratories, India). 1 $\mathrm{mL}$ of the inoculation solution was used for inoculating a test tube containing $4 \mathrm{~mL}$ of Molar- Hinton broth and silver NPs, The final concentrations of silver NPs were 200, 40, 8, 1.6 and $0.32 \mu \mathrm{g} / \mathrm{mL}$, respectively. Positive and negative control tubes were included for each isolate. Then, the tubes were incubated at $37^{\circ} \mathrm{C}$ for 20 h. The lowest concentrations that prevented any visible growth were considered as the MIC value.

\section{Anticancer activity Cell line and cell culture}

The human breast adenocarcinoma (MCF7) and human mammary epithelial (MCF10A) cell lines were purchased from American Type Culture Collection (Manassas, VA) and cultured and maintained in RPMI-1640 media containing 10\% fetal bovine serum (FBS), 100 units $/ \mathrm{mL}$ of penicillin, and 50 units $/ \mathrm{mL}$ of streptomycin at $37{ }^{\circ} \mathrm{C}$ in an incubator containing $5 \%$ $\mathrm{CO}_{2}$.

\section{Cell viability assay}

Cell proliferation was examined by a MTT assay depending on the capability of cells to convert MTT to a purple formazan dye. MTT (3-[4, 5-dimethylthiazol2-yl] 2, 5-iphenyltetrazolium bromide) test was performed to evaluate the in-vitro cytotoxicity effect of bare silver NPs, extract based silver NPs and free extract on the human breast adenocarcinoma (MCF7) and human mammary epithelial (MCF10A) cell lines. First $200 \mu \mathrm{L}$ medium inclosing $1 \times 10^{4}$ cells was added into each well of a 96 well cell culture plate. After adhering and growing cells for $24 \mathrm{~h}$, the medium of each well was thrown away and replaced with fresh ones comprising different concentrations ( 0 to $120 \mu \mathrm{g}$ ) $\mathrm{mL}$ ) of free extract, extract based silver NPs and silver NPs separately. The extract based silver NPs treated cells were incubated for 24 and $48 \mathrm{~h}$, and the free extract and bare silver NPs treated cells just for $48 \mathrm{~h}$. The cells without any treatment or just subjected to medium environment was considered as control group. The 10 $\mu \mathrm{L}$ of $5 \mathrm{mg} / \mathrm{mL}$ MTT solution was added to each 100 $\mu \mathrm{L}$ media contained well in 96 cell culture plates. The plates were then incubated at cell culture incubator with optimized conditions (temperature at $37{ }^{\circ} \mathrm{C}$ and humidified atmosphere containing 95\% air and 5\% $\mathrm{CO}_{2}$ ) for $4 \mathrm{~h}$. In the next step, all of the solution in the wells was removed and substituted with $100 \mu \mathrm{L}$ of DMSO in order to dissolve the formazan crystals. The plates were placed on shaker for 5 min to complete the dissolution process of formazan crystals. Then, the absorbance was settled at $540 \mathrm{~nm}$ utilizing a multi scan plate reader (Biochrom Asys Expert 96, U.K.). The absorbance of DMSO was considered for each of the recorded samples. All experiments were prescribed in triplicates and repeated twice for statistical analysis. Cell toxicity amount was obtained by Eq (1) and the results were expressed as mean $\pm \mathrm{SD}$

Relative cell viability $=\left[\mathrm{A}_{\text {sample }}-\mathrm{A}_{\text {control }}\right] / \mathrm{A}_{\text {control }} \times 100$.

\section{Apoptosis assay}

To investigate the level of cell apoptosis, initially, the cells were treated with different treatments of palm dates synthesized silver NPs, free extract and silver NPs at $48 \mathrm{~h}$. Cells alone in culture media were considered as negative control. All groups were harvested using trypsin and centrifuged at $400 \mathrm{~g}$ for $3 \mathrm{~min}$. Afterwards, the obtained pellet re-suspended with $500 \mu \mathrm{L}$ of $1 \times$ binding buffer and treated with 5 $\mu \mathrm{L}$ of Annexin V-FITC and $5 \mu \mathrm{L}$ Propidium Iodide (PI). The samples were mixed and incubated for 10 
min at room temperature. Subsequently, the samples were transferred to FACS tubes for analysis in a flow cytometer (BD Bioscience FACS, USA).

\section{Statistical analysis}

The experiments were repeated at least three separate times. Statistical analysis was performed with Sigma Plot (London, UK). A p-value of $\leq 0.05$ was considered statistically significant.

\section{Results and Discussion}

\section{Synthesis and characterization of silver nanoparticles}

It was demonstrated that silver NPs were synthesized by Aloevera plant extract as a reducing agent and stabilizer. However, the reduction process to form silver NPs needed $24 \mathrm{~h}$ at room temperature [2]. In this research, we reported the use of Iraqi Zahdi palm dates as reducing and stabilizing agents which were mixed with silver nitrates for $15 \mathrm{~min}$ at $90^{\circ} \mathrm{C}$ to synthesize silver NPs. The reason behind utilization of Zahdi palm dates was they showed high content of polyphenols [29] which donated an electron to silver ion $\left(\mathrm{Ag}^{+}\right)$to form silver NPs on one hand. On the other, these polyphenols compounds acted as capping agent through coating the surface of the formed NPs to avoid the aggregation causing an increase in the stability. The reduction process was monitored by the observation of the color change and the change in the intensity of the absorption band at around 400-450 $\mathrm{nm}$. A significant color change from pale yellow to dark brown was observed, along with the absorption increment at that wavelength range referring to the progress of the reduction reaction which was a visual and clear evidence of the formation of silver NPs [31]. Figure 2 shows the UV-visible spectrum of the prepared silver NPs. It could be seen in the figure that silver NPs absorbed in the visible region at around 400 $\mathrm{nm}$ while the crude extract was colorless. Additionally, the figure also shows the influence of reaction time on the formation of silver NPs whereby the reaction showed a maximum absorption spectrum (about 2) after 15-20 min. However, the absorption peak started decline as the time increased over 30 min (absorbance is about 1) due to the fact that the multi-components of palm dates extract and silver ions might interact with the synthesized silver NPs causing aggregation of nano sized silver. However, it overcame such potential issue through purifying the synthesized silver NPs solution firstly with 0.2 micron filter syringe and then with 12 $14 \mathrm{kDa}$ dialysis bag to get rid of extract components and residue silver ions. These changes in color as well as wavelength were attributed to two main reasons: Firstly, the fast change of surface plasmon resonance (SPR) of silver NPs belonged to the external applied UV-visible spectrum. Secondly, the existence of surface electrons of produced silver NPs caused collective oscillation [12, 26]. The figure also shows the broadening band of silver NPs because of the polydispersity of formed NPs which might be due to increase in the concentration of the extract [26, 32, 33].

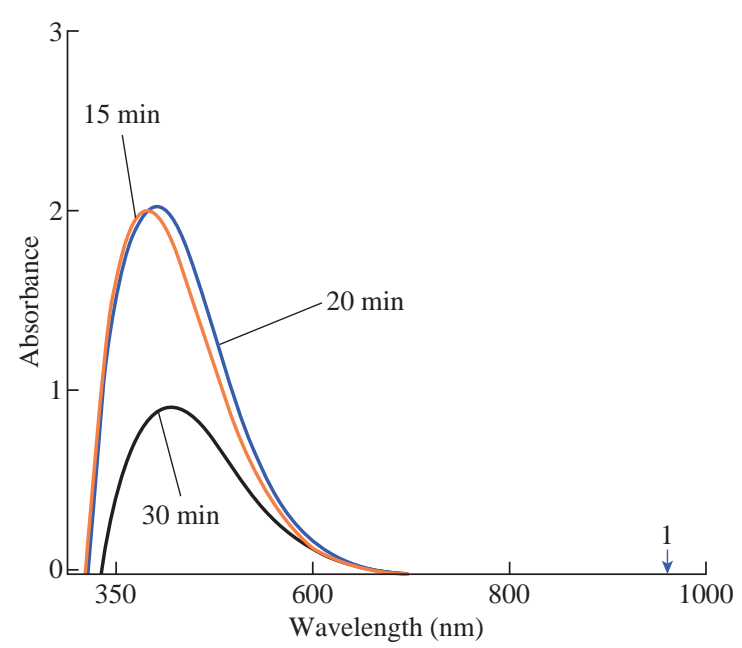

Fig. 2 The UV-visible spectrum of synthesized silver nanoparticles using crude Zahdi palm dates extract using distilled water as a blank. The nanoparticles were prepared by addition of aliquot of silver nitrate to excess amount of Zahdi palm dates extract. Then the produced mixture was heated up to $90{ }^{\circ} \mathrm{C}$ for 15 minutes with stirring in the absence of light. A dark brown suspension was formed confirming the formation of silver nanoparticles which characterized by UV-visible spectrophotometer in the wavelengths ranged from $325 \mathrm{~nm}$ to $750 \mathrm{~nm}$. The results appeared a maximum wavelength at around $430 \mathrm{~nm}$ which is a clear evidence of the synthesis of silver NPs.

The particle size distribution and zeta potential of synthesized silver NPs are shown in Fig. 3. Fig. 3(a) describes that the average particle diameter of the NPs was in the range from $60 \mathrm{~nm}$ to $130 \mathrm{~nm}$ with polydispersity index of around 0.166 , confirming that this value suggests the formation of almost monodispersed silver NPs. The zeta potential analysis of the prepared NPs displayed that palm dates extract capped silver NPs had negative charge of $-25 \mathrm{mV}$ as stated in Fig. 3(b). These results are in good agreement with that for broadening peak of UV-Vis spectrum of the synthesized NPs. Table 1 reveals the particle size distribution and zeta potential measurements of green synthesized silver NPs alone in aqueous solutions and 
Table 1 Stability of ecofriendly synthesized silver nanoparticle in aqueous solution and in the presence of phosphate buffer saline (PBS) and culture medium

\begin{tabular}{|c|c|c|c|c|}
\hline & Bare silver NPs & $\begin{array}{l}\text { Green synthesized } \\
\text { silver NPs }\end{array}$ & $\begin{array}{l}\text { Green synthesized } \\
\text { silver NPs in PBS }\end{array}$ & $\begin{array}{l}\text { Green synthesized silver } \\
\text { NPs in culture medium }\end{array}$ \\
\hline Average particle diameter (nm) & $150 \pm 28$ & $80 \pm 20$ & $100 \pm 30$ & $140 \pm 30$ \\
\hline Zeta potential (mV) & $-45 \pm 5$ & $-25 \pm 5$ & $-23 \pm 10$ & $-15 \pm 4$ \\
\hline Polydispersity index (PDI) & 0.362 & 0.166 & 0.151 & 0.179 \\
\hline
\end{tabular}
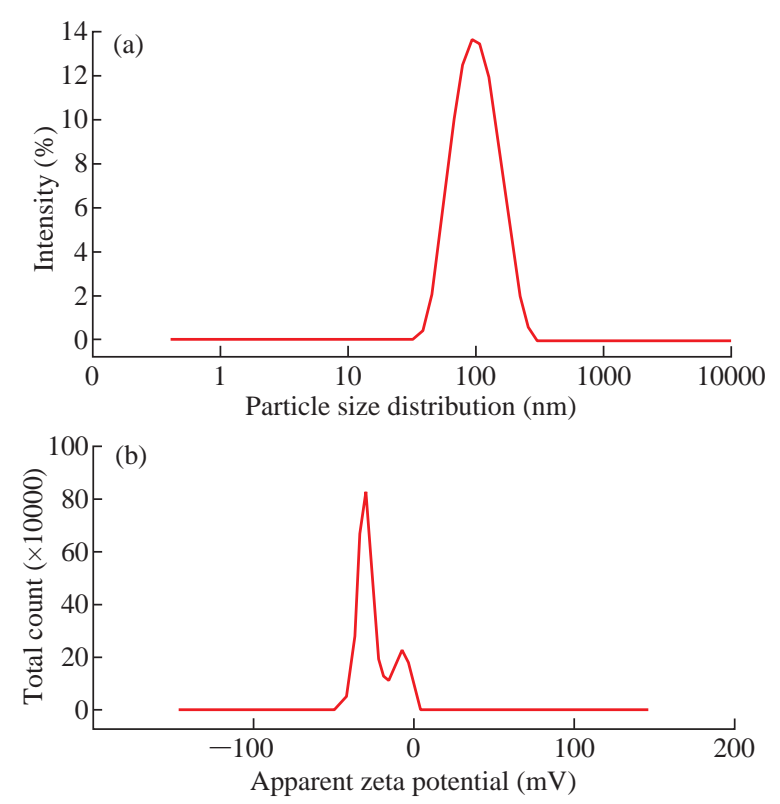

Fig. 3 (a) The average particle diameter and (b) zeta potential measurements of as prepared silver nanoparticles capped with Zahdi palm dates extract which is used as reducing and stabilizer agent in the synthesis of silver nanoparticles. The particle size and zeta potential of silver nanoparticles were conducted by using Malvern Zetasizer Nano ZS at room temperature $\left(25^{\circ} \mathrm{C}\right)$ using clear and clean plastic cuvette while for zeta potential analysis, it was performed by dip-cell that inserted into $1.5 \mathrm{~mL}$ aliquot of silver NPs filled plastic cuvette.

in the presence of phosphate buffer saline (PBS) and RPMI-1640 culture medium to study the colloidal stability of green synthesized silver NPs. It is shown that the average particle diameter and zeta potential of bare green synthesized silver NPs were $80 \mathrm{~nm}$ and $-25 \mathrm{mV}$, respectively. However, upon dispersion of the prepared silver NPs in PBS, it was observed that the particle size slightly increased to $100 \mathrm{~nm}$ with -23 zeta potential. This alteration was due to the $\mathrm{pH}$ change and the increase of ionic strength coming from buffer ions. Also, in case of the ecofriendly synthesized silver nanoparticles dispersed in culture medium, the particle size and zeta potential pronounced change to 140 $\mathrm{nm}$ and $-15 \mathrm{mV}$, respectively, which was considered as greater change for green synthesis because of functionalization of positively charged protein content in the culture media with negatively charged silver
NPs, leading to increase of the particle size and decrease in the zeta potential.

These results are in line with Ilknur et al. who observed that upon mixing of silver NPs dispersion with culture media, the surface charge of NPs declined because of the adsorption of the serum protein onto the surface of NPs in comparison with bare silver NPs [34]. Thus, the suspension was maintained with good stability in the solution over a long period (over six months) as the synthesized silver NPs were sufficiently charged. The synthesis of silver NPs was also confirmed by XRD patterns that were recorded in the $\theta$ range 20 to $60^{\circ}$ as shown in Fig. 4(a). The characteristics of XRD pattern showed diffraction peaks at $38^{\circ}$ and $44.3^{\circ}$ correspond to (111) and (200) planes, respectively. The (111) peak at $38^{\circ}$ clearly demonstrated a strong diffraction intensity with good crystalline nature, indicating the preferential orientation of silver crystal. These peaks were identified to be polycrystalline which were in line with the face center
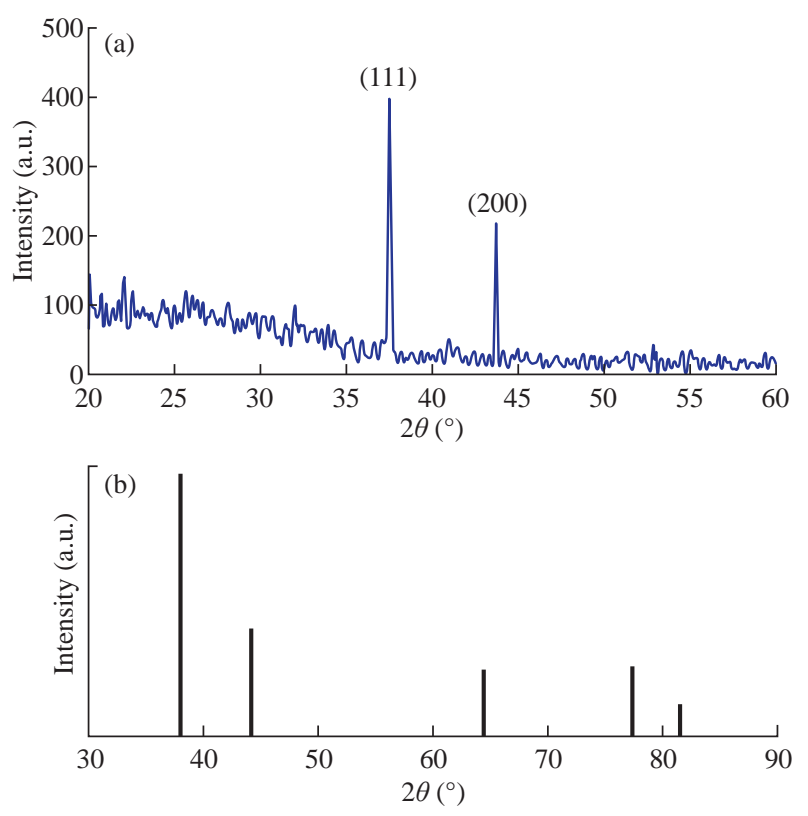

Fig. 4 (a) The X-ray diffraction patterns of synthesized silver nanoparticles through reduction of silver nitrate solution with Zahdi palm dates extract for 15 minutes at $90^{\circ} \mathrm{C}$. (b) JCPDS file No. 04-0783. 
cubic (FCC) structure of silver crystal according to International Center of Diffraction Data (JCPDS ICDD) card No. \#96-151-2488 with JCPD file No. 040783 as shown in Fig. 4(b). The crystallite domain size of Ag NPs was calculated from Scherrer's equation [4]:

$\mathrm{D}=0.94 \lambda /(\beta \cos \theta)$,

where $\mathrm{D}$ is the crystallite size, $\lambda$ is the wavelength of X-ray used (1.5406 $\AA$ ), $\beta$ is the full width at half maximum (FWHM) and $\theta$ is the Bragg's angle. The average domain crystallite sizes of synthesized silver NPs were measured to be $21 \mathrm{~nm}$ and $17 \mathrm{~nm}$ for (111) and (200) planes.

The crystallite nature of synthesized silver NPs by Zahdi palm dates extract was also characterized in terms of topography by AFM technique. It can be seen in Figure 5 that the grain size of Ag NPs was found to be in the range from 20 to $150 \mathrm{~nm}$ with polycrystalline nature. These results were in good agreement with that for both dynamic light scattering and $\mathrm{X}$-ray diffraction as shown above in Fig. 3 and 4, respectively.
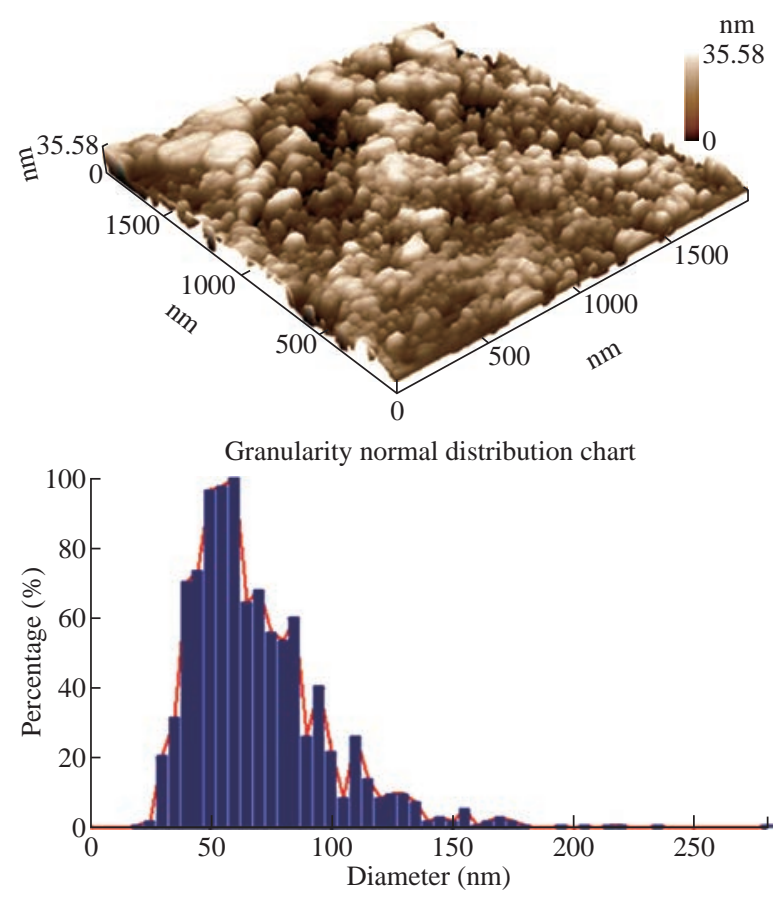

Fig. 5 The AFM topographical image with grain size distribution of silver nanoparticles synthesized by reduction of silver nitrate solution with the palm dates extract at $90{ }^{\circ} \mathrm{C}$ for 15 min.

Fig. 6 shows FTIR spectrum of synthesized silver NPs in the wavelength range from 500 to $4000 \mathrm{~cm}^{-}$ ${ }^{1}$. It can be seen in the figure that the FTIR spectrum showed absorption bands at 1110, 1380, 1460, 1637 and $3332 \mathrm{~cm}^{-1}$. The stretching vibration band at 1110 $\mathrm{cm}^{-1}$ and $1460 \mathrm{~cm}^{-1}$ represented the hydroxyl functional groups of polyphenols and phenols, respectively. The absorption band at $1380 \mathrm{~cm}^{-1}$ was attributed to $\mathrm{C}-\mathrm{N}$ stretching vibration or $\mathrm{O}-\mathrm{H}$ bending vibrations. The peak at $1637 \mathrm{~cm}^{-1}$ was designated to vibration stretching group $\mathrm{C}=\mathrm{O}$ indicating the carboxylic acids group which was bound to silver NPs. The peak at $3332 \mathrm{~cm}^{-1}$ was owing to $\mathrm{O}-\mathrm{H}$ stretching vibration band for polyphenolic compounds in the extract adsorbed on the surface of the NPs as well as the presence of water into the system, and thereby intermolecular hydrogen-bonding. All these stretching vibrations bands illustrated that carboxylic groups, amide groups and polyphenolic groups were functionalized on the surface of silver NPs causing increase the stability of the synthesized NPs with minimal aggregation. The surface morphology studies and elementary analysis of synthesized silver NPs were also performed by SEM-EDX to confirm the formation of nano-scale of silver particles. Fig. 6 describes SEM images and EDX analysis with various magnifications of dried film of silver NPs that were drop casted onto aluminum foil. Fig. 6(a) and (b) illustrate that silver NPs were spherical-like shape with polycrystalline nature whereby the average particle sizes were at around 50 to $150 \mathrm{~nm}$. These sizes were in good agreement with that for particle size distributions of dynamic light scattering (DLS) and atomic force microscope (AFM) of synthesized silver NPs. Fig. 6(c) displays EDX spectrum with a strong optical absorption peak at $3 \mathrm{eV}$ which referred to the formation of silver NPs [12]. The morphology and size of the palm dates based silver NPs were also evaluated by TEM method as shown in Fig. 7. The analysis of TEM images revealed that most of the NPs had smooth spherical morphology with negligible polydispersity. These NPs were almost in a single situation and were not accumulated and had

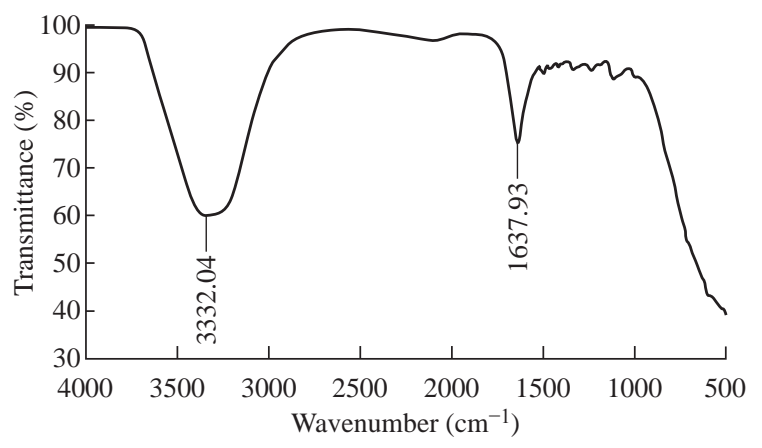

Fig. 6 FTIR spectrum of synthesized silver nanoparticles by Zahdi palm dates extract as a reducing and stabilizing agents. The measurement was conducted using ATR technique with Bruker FTIR instrument. 

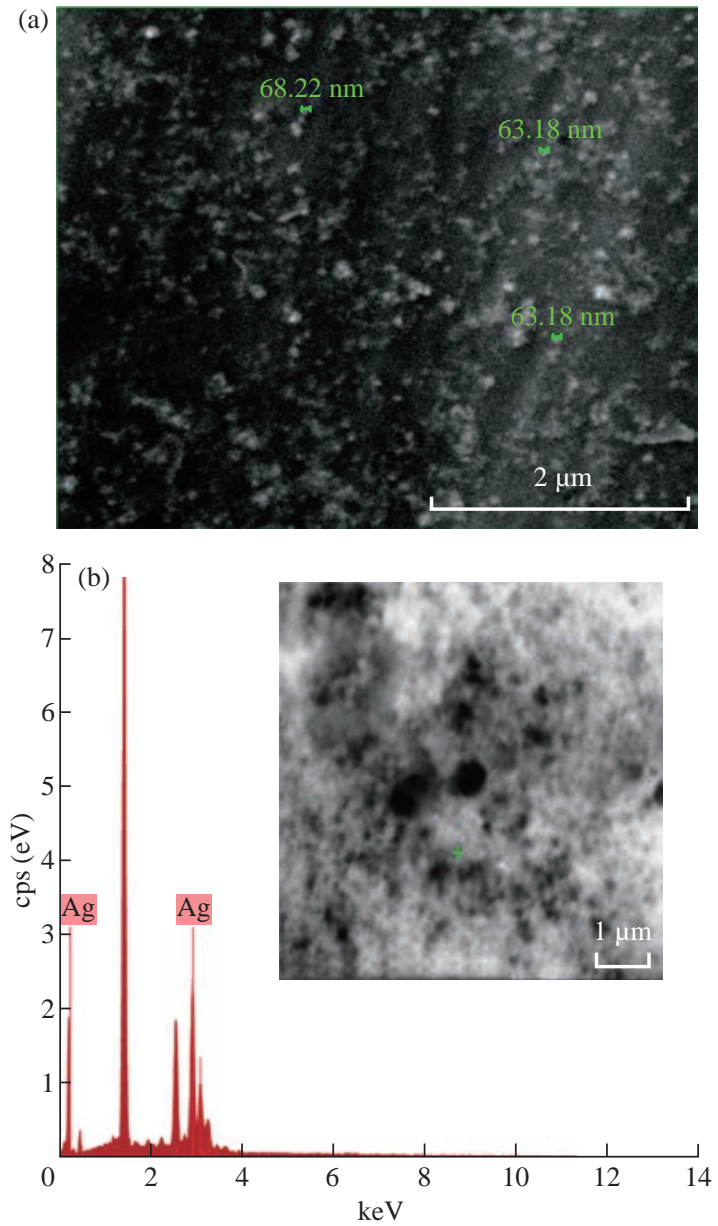

Fig. 7 (a) The SEM images and elementary analysis of dried thin film of synthesized silver nanoparticles with scale bar at 2 $\mu \mathrm{m}$. (b) EDX analysis of formation of silver NPs at 3 confirming the production of silver NPs.

average size of about $50 \mathrm{~nm}$.

\section{Antibacterial activity of green synthesized silver nanoparticles}

The antimicrobial activity of silver NPs that were

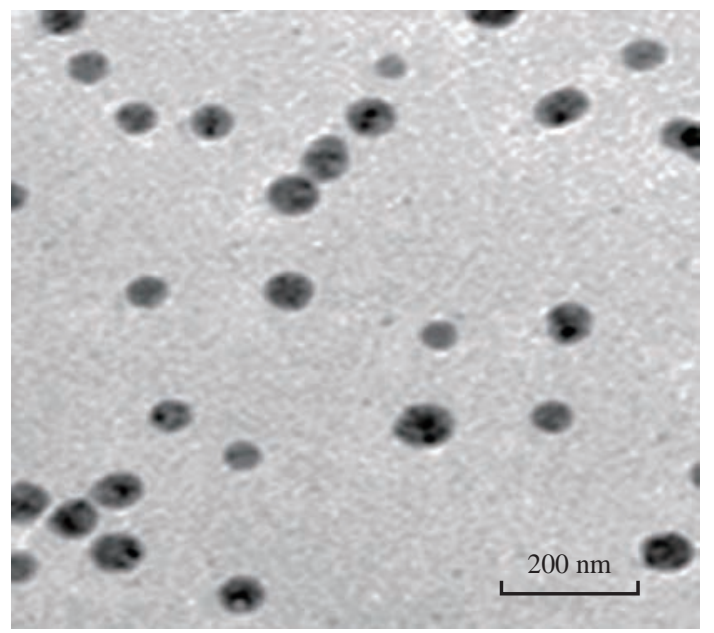

synthesized by the utilization of Zahdi palm dates extract as reducing and capping agents were carried out by macro-dilution assay. Fig. 9 displays images of MRSA bacteria incubated with synthesized silver NPs solutions for $24 \mathrm{~h}$ at $37^{\circ} \mathrm{C}$. Table 2 shows the minimum inhibitory concentration (MIC) values of group of MRSA bacteria against series of solutions of silver NPs concentrations (200-0.32 $\mu \mathrm{g} / \mathrm{mL}$ ) for 24 $\mathrm{h}$ incubation time at $37^{\circ} \mathrm{C}$. It could be demonstrated in the table that robust antibacterial actions clearly appeared at $40 \mu \mathrm{g} / \mathrm{mL}$ of silver NPs concentration against Staphylococcus epidermidis, while at higher concentration $(200 \mu \mathrm{g} / \mathrm{mL})$ of silver NPs, pronounced inhibition was observed towards group of $V$. fluvialis, P. aeroginosa, S. marcescens, A. hydrophila, E. coli, E. faecalis, and K. pneumonia. On the other hand, M. morganii and S. aureus had slightly shown antibacterial activity and they needed as greater silver NPs concentration as $200 \mu \mathrm{g} / \mathrm{mL}$ to improve the activity. The reason behind antimicrobial action of silver NPs is related to some potential mechanisms such as direct internalization of NPs which leads to cell death, generation of reactive oxygen species (ROS) such as hydrogen peroxide, hydroxyl, and superoxide radicals, electrostatic interaction between the surface charge of nanomaterial, and the opposed charge on the outer cell wall membrane of microorganism [4]. Silver NPs could also release cationic silver ions which either bound with proteins of outer membrane of bacteria causing denaturation or penetrate through cell wall into cytoplasm making cell damage and death [35]. Additionally, the variation in the cell wall membrane of such bacteria could play vital role in the enhancement of antimicrobial activity of silver NPs because of the

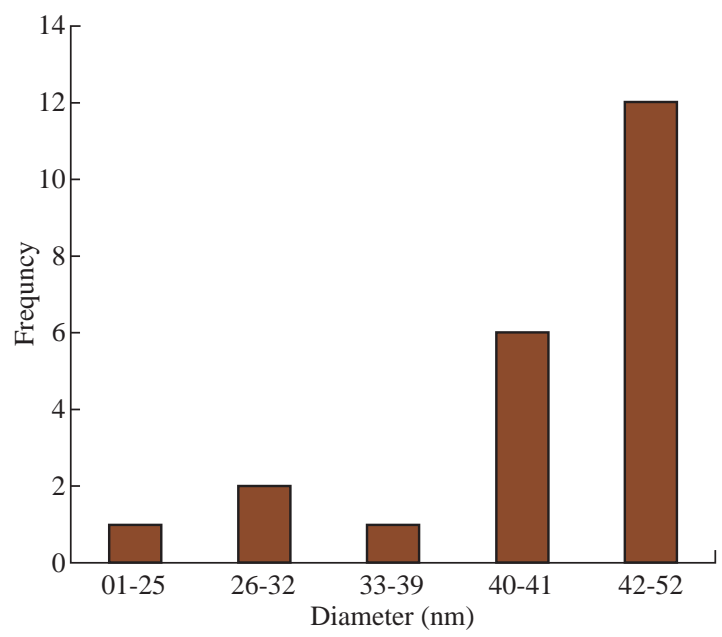

Fig. 8 TEM image of dried thin film of palm dates synthesized silver nanoparticles at $200 \mathrm{~nm}$ scale bar. The histogram reflects the average particle diameter in nanometer of synthesized silver nanoparticles which explains that the average diameter was $50 \mathrm{~nm}$. 

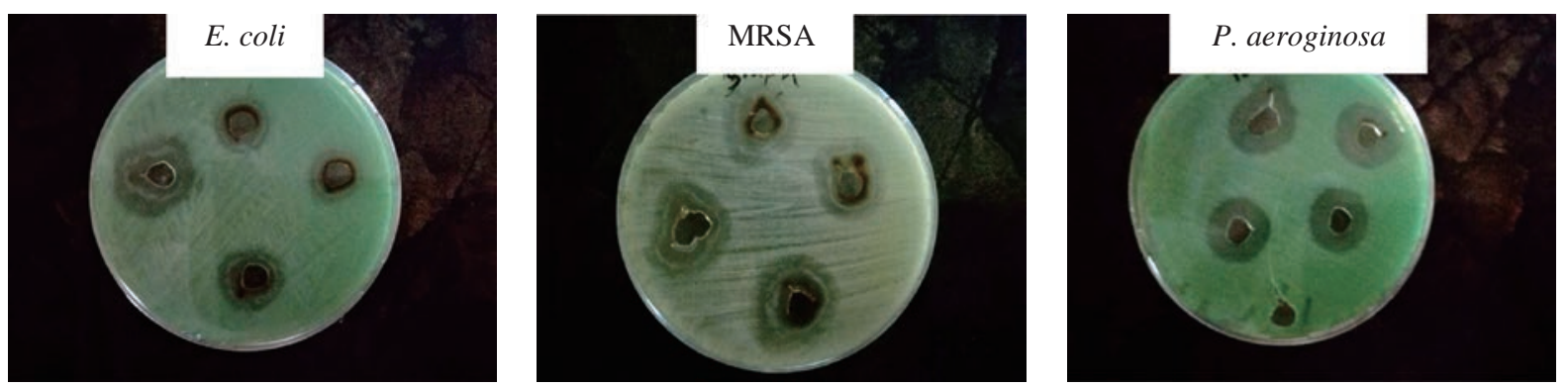

Fig. 9 Antibacterial activity of palm dates based silver nanoparticles towards some gram-negative bacteria such as E. coli and grampositive bacteria including MRSA and $P$. aeroginosa bacteria. The incubation time was conducted at $37^{\circ} \mathrm{C}$ for $24 \mathrm{~h}$. The synthesized nanoparticles showed efficient biological activity towards such microorganisms.

Table 2 The minimum inhibitory concentration (MIC) values of MRSA bacteria upon incubation with varied solutions of different concentrations of nanosilver suspension for $24 \mathrm{~h}$ at $37^{\circ} \mathrm{C}$, p-value less than 0.05

\begin{tabular}{cc}
\hline Bacterial isolate & Minimum inhibitory concentration $(\mathrm{MIC}) *(\mu \mathrm{g} / \mathrm{mL}), p<0.05$ \\
\hline Aeromonas hydrophila & 200 \\
Escherichia coli & 200 \\
Enterococcus faecalis & 200 \\
Klebsiella pneumonia & 200 \\
Morganella morganii & $>200$ \\
Pseudomonas aeroginosa & 200 \\
Serratia marcescens & 200 \\
Staphylococcus aureus & $>200$ \\
Staphylococcus epidermidis & 40 \\
Vebrio fluvialis & 200 \\
\hline
\end{tabular}

*The MIC values of solutions of silver nanoparticles concentrations were prepared with respect to $1000 \mu \mathrm{g} / \mathrm{mL}$ stock solution of as prepared nanosilver suspension.

differences in the cell wall thickness of both gram positive and gram negative bacteria $[4,12]$.

\section{In-vitro cytotoxicity and apoptosis assay of green synthesized silver nanoparticles}

The in vitro anticancer effects of dates extract based silver NPS against human breast adenocarcinoma (MCF7) and human mammary epithelial (MCF10A) cell lines were estimated using MTT assay as stated in Fig. 10. The cell viability was conducted through incubation of MCF7 cells and MCF10A cells individually with solutions of different concentrations of green synthesized silver NPs for $24 \mathrm{~h}$ and $48 \mathrm{~h}$ at $37^{\circ} \mathrm{C}$ to investigate the anticancer activity of the synthesized silver NPs towards breast cancer cells as compared with normal cells. It can be seen in Fig. 10(a) that at $24 \mathrm{~h}$ incubation time, sharp decreases were considerably observed in the viability of MCF7 cells (above 75\% dead cells) upon incubation with 80-120 $\mu \mathrm{g} / \mathrm{mL}$ of the green synthesized silver NPs (red bar), while at low concentrations of the synthesized silver NPs, $50 \%$ viable cells were markedly pronounced in the same time. After $48 \mathrm{~h}$, the green silver NPs incubated MCF7 cells showed minor declines in the viability for all concentrations as stated in Fig. 10(b). Despite the fact that there was no obvious cytotoxic effect in case of normal MCF10A cell line (blue bar) for both periods of incubation time. Moreover, the void extract treated groups indicated a negligible toxic effect on cancer and normal cell lines up to $48 \mathrm{~h}$. Our findings indicated that green synthesized silver NPs boosted the anticancer activity on MCF7 cells causing cell death. The obtained IC50 value for MCF7 cell lines was for $24 \mathrm{~h}$ and $48 \mathrm{~h}$, whereby standard curve method was applied to calculate the $50 \%$ of inhibited concentration of cell growth (IC50). It could be also seen in Fig. 10 that green synthesized silver NPs showed cytotoxic activity towards MCF7 cancerous cells, while there was no pronounced toxic effect in the presence of MCF10A normal cell line. As previously mentioned, palm dates contains high content of antioxidants compounds such as phenolic acid, flavonoids, alkaloids and terpenoids. These compounds are safe towards normal cells while they have cytotoxicity with cancerous cells [36-38]. Hence, the synthesized silver NPs coated with such materials have shown non-toxic effect upon incubation with normal cells. In addition to that, nano silver has high activity due to their large surface to volume ratio 

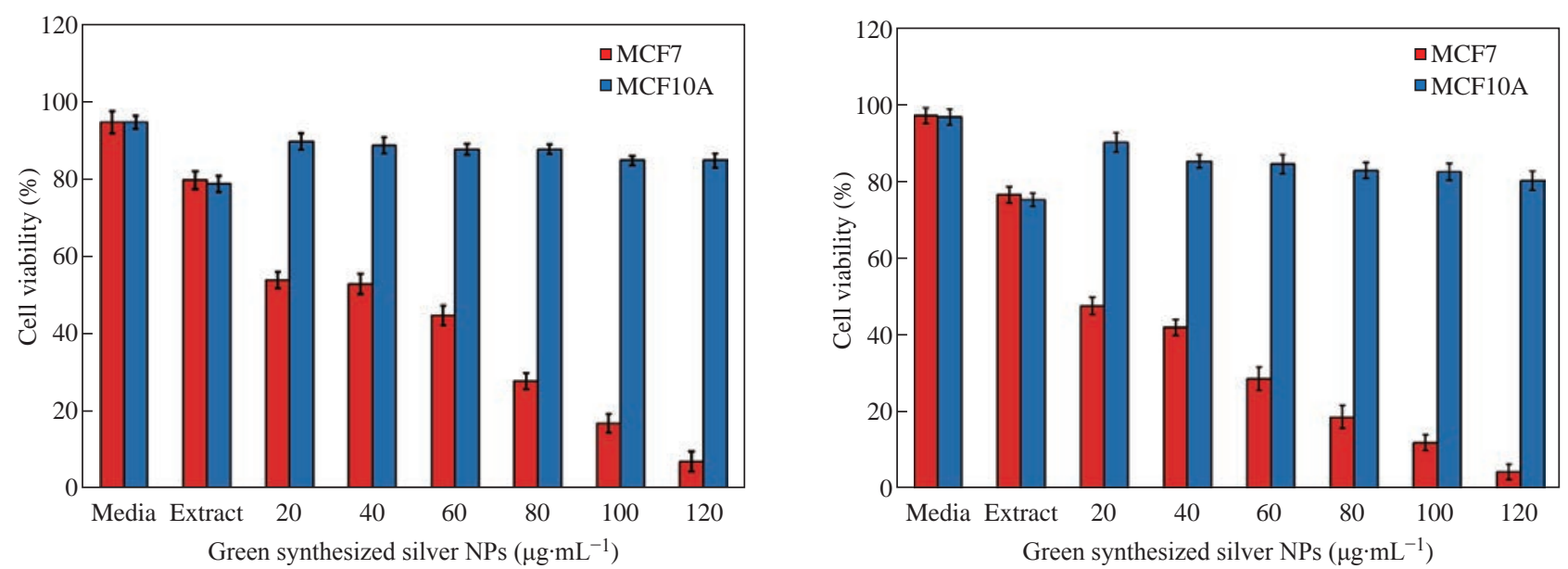

Fig. 10 Cell viability assay of human breast adenocarcinoma (MCF7) and human mammary epithelial (MCF10A) cell lines incubated with solutions of different concentrations of: (a) Palm extract based silver NPs at 24 h; and (b) palm extract based silver NPs at $48 \mathrm{~h}$. The percentages of viable cells are shown as mean \pm standard deviations of triplicate independent experiments $(p \leq 0.05)$.
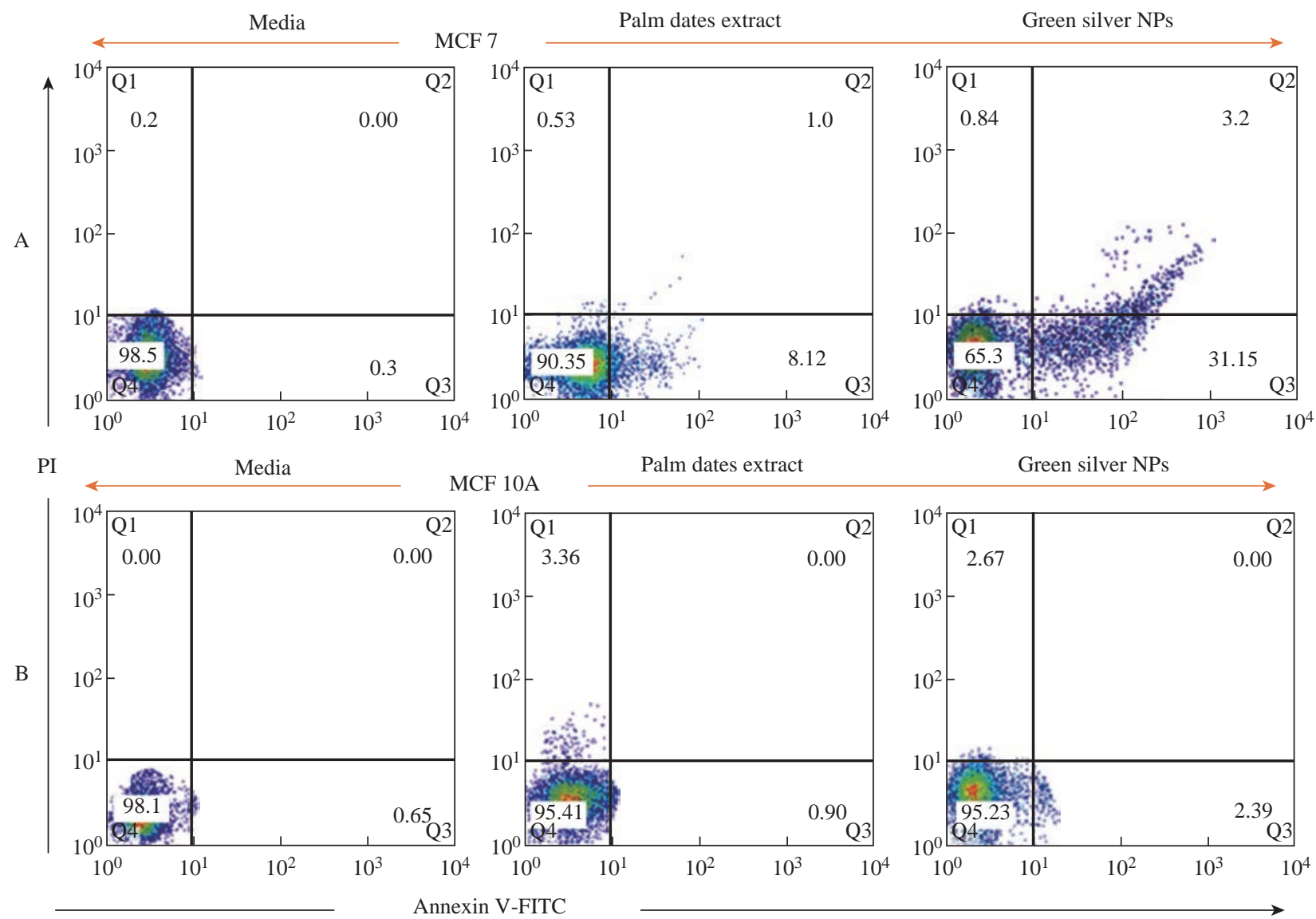

Fig. 11 Apoptosis inducted by green synthesized silver NPs and free extract on MCF7 and MCF10A cell lines. The number of MCF7 cells undergoing apoptosis significantly increased upon treatment with green silver NPs, while the normal MCF10A cell lines did not indicate any significant effect of apoptosis induction with same treatment. Moreover, treatment of MCF7 cell lines with free extract indicated that there was not appearance of any remarkable apoptosis process as well as normal MCF10A cell lines.

as well as the high affinity of cancerous cells for green synthesized silver NPs. This approach could let the NPs to internalize and interact with cell components precisely, mitochondria and damage the cellular electron transfer chain function leading to an increase in the ROS level, generating oxidative stress [39]. Such effective anticancer of green synthesized nano silver could be attributed to synergistic effect between silver 
NPs and the covering antioxidents.

Mitochondria was taken into consideration as an integration point for apoptotic signals generating from both the extrinsic and intrinsic apoptotic pathways [40]. Many studies have shown that the apoptosis activation plays a vital role in inhibiting the growth and development of cancers [33]. Thus, for further exploring the mechanisms of inhibitory impacts of green synthesized silver NPs on MCF7 and MCF10A cells, Fig. 11 shows the apoptosis that was evaluated using an Annexin V-FITC/PI apoptosis detection kit, flow cytometry and FlowJo-cell cycle analysis software for flow cytogram analysis. The X- and Y-axes are designated to Annexin V-FITC staining and PI, respectively. As shown in Fig. 11(a), a remarkable increase in the percentage of apoptotic cells was perceived for palm dates extract based silver NPs in the case of MCF7 cell lines in comparison with that of normal cells. Precisely, the green synthesized silver NPs changed cell morphology, inhibited the growth and led to significant apoptosis effect in MCF7 cancer cell lines, whereas had no significant effect on normal cells as stated in Fig. 11(b). The Cytogram analysis also confirmed that the palm dates extract clearly indicated that there was a negligible apoptotic induction with free extract in cancer cell lines without any noticeable effect in normal cells. All experiments were achieved with triplicate independent experiments $(p \leq 0.05)$.

\section{Conclusions}

Zahdi palm dates extract is considered as a great reducing and capping agents that contributes to the green synthesis of nano-sized silver particles. The absorption spectrum of synthesized NPs appeared maximum wavelength at $400 \mathrm{~nm}$ which represented the surface plasmin resonance band of silver NPs. he stability of the prepared nano silver suspension was also measured, and the results illustrated that average particle diameter and zeta potential of the synthesized NPs were around $90 \mathrm{~nm}$ and $-25 \mathrm{mV}$, respectively. Also, the polydispersity index was 0.166 , which meant that the silver NPs were monodispersed. The AFM and SEM found a similar range of particle size distributions which were in line with that found by dynamic light scattering technique. FTIR spectrum confirmed that the synthesized silver NPs were functionalized with some carboxylic, phenols, and polyphenols groups that improved the stability of silver NPs and stayed with no observed aggregation for a long period of time. XRD patterns showed that the synthesized silver NPs possessed polycrystalline nature with face centre cubic (FCC) structure of silver crystal according to International Center of Diffraction Data. Further, the ecofriendly synthesized silver NPs have presented a significant antibacterial effect against grampositive and gram negative bacteria. Silver NPs also demonstrated a significant anticancer efficacy against breast cancer (MCF7) as compared to normal cell line (MCF10A). Therefore, it can be concluded that green synthesized silver NPs could open the door for other biomedical applications such as wound healing and dressing.

\section{Acknowledgements}

Authors would like to thank SEM Section Team at the University of Babylon, Babylon, Iraq and Dr. Mohammed Sabbar, College of Pharmacy, Basrah University, Basrah, Iraq for their generous contributions in the conduction of this article.

\section{Conflict of Interest}

The authors declare that no competing interest exists.

\section{References}

[1] P. Hartemann, P. Hoet, A. Proykova, et al., Nanosilver: Safety, health and environmental effects and role in antimicrobial resistance. Materials Today, 2015, 18(3): 122-123.

[2] S.P. Chandran, M. Chaudhary, R. Pasricha, et al., Synthesis of gold nanotriangles and silver nanoparticles using Aloevera plant extract. Biotechnology Progress, 2006, 22(2): 577-583.

[3] S.T. Stern, S.E. McNeil, Nanotechnology safety concerns revisited. Toxicological Sciences, 2007, 101(1): 4-21.

[4] M.J. Al-Awady, G.M. Greenway, and V.N. Paunov, Nanotoxicity of polyelectrolyte-functionalized titania nanoparticles towards microalgae and yeast: Role of the particle concentration, size and surface charge. RSC Advances, 2015, 5(46): 37044-37059.

[5] W.H., Mohammed, W.K. Ali, and M.J. Al-Awady, Evaluation of in vitro drug release kinetics and antibacterial activity of vancomycin HCl-loaded nanogel for topical application. Journal of Pharmaceutical Sciences and Research, 2018, 10(11): 2747-2756.

[6] M.J. Al-Awady, A. Fauchet, G.M. Greenway, et al., Enhanced antimicrobial effect of berberine in nanogel carriers with cationic surface functionality. Journal of Materials Chemistry B, 2017, 5(38): 7885-7897.

[7] M.J. Al-Awady, P.J. Weldrick, M.J. Hardman, et al., Amplified antimicrobial action of chlorhexidine encapsulated in PDAC-functionalized acrylate copolymer 
nanogel carriers. Materials Chemistry Frontiers, 2018, 2: 2032-2044.

[8] L. Suber, I. Sondi, E. Matijević, et al., Preparation and the mechanisms of formation of silver particles of different morphologies in homogeneous solutions. Journal of Colloid and Interface Science, 2005, 288(2): 489-495.

[9] Y.C.Liu, L.H. Lin, New pathway for the synthesis of ultrafine silver nanoparticles from bulk silver substrates in aqueous solutions by sonoelectrochemical methods. Electrochemistry Communications, 2004, 6(11): 11631168.

[10] C.H. Bae, S.H. Nam, and S.M. Park, Formation of silver nanoparticles by laser ablation of a silver target in $\mathrm{NaCl}$ solution. Applied Surface Science, 2002, 197-198: 628634.

[11] M.N. Nadagouda, T.F. Speth, and R.S. Varma, MicrowaveAssisted Green Synthesis of Silver Nanostructures. Accounts of Chemical Research, 2011, 44(7): 469-478.

[12] M. Gomathi, P. Rajkumar, A. Prakasam, et al., Green synthesis of silver nanoparticles using Datura stramonium leaf extract and assessment of their antibacterial activity. Resource-Efficient Technologies, 2017, 3(3): 280-284.

[13] C.L. Kitchens, M.C. McLeod, and C.B. Roberts, Chloride Ion Effects on Synthesis and Directed Assembly of Copper Nanoparticles in Liquid and Compressed Alkane Microemulsions. Langmuir, 2005, 21(11): 5166-5173.

[14] J. Liu, F. He, T.M. Gunn, et al., Precise seed-mediated growth and size-controlled synthesis of palladium nanoparticles using a green chemistry approach. Langmuir, 2009, 25(12): 7116-7128.

[15] S.K. Das, M.M.R. Khan, T. Parandhaman, et al., Nanosilica fabricated with silver nanoparticles: antifouling adsorbent for efficient dye removal, effective water disinfection and biofouling control. Nanoscale, 2013, 5(12): 5549-5560.

[16] A. Mandal, V. Meda, W. Zhang, et al., Synthesis, characterization and comparison of antimicrobial activity of PEG/TritonX-100 capped silver nanoparticles on collagen scaffold. Colloids and Surfaces B: Biointerfaces, 2012, 90: 191-196.

[17] A. Mandal, S. Sekar, K.M.S. Meera, et al., Fabrication of collagen scaffolds impregnated with sago starch capped silver nanoparticles suitable for biomedical applications and their physicochemical studies. Physical Chemistry Chemical Physics, 2014, 16(37): 20175-20183.

[18] A. Mandal, S. Sekar, N. Chandrasekaran, et al., Synthesis, characterization and evaluation of collagen scaffolds crosslinked with aminosilane functionalized silver nanoparticles: In vitro and in vivo studies. Journal of Materials Chemistry B, 2015. 3(15): 3032-3043.

[19] M. Rafique, I. Sadaf, M.S. Rafique, et al., A review on green synthesis of silver nanoparticles and their applications. Artificial Cells, Nanomedicine, and Biotechnology, 2016: 1-20.

[20] A. Bankar, B. Joshi, A.R. Kumar, et al., Banana peel extract mediated novel route for the synthesis of silver nanoparticles. Colloids and Surfaces A: Physicochemical and Engineering Aspects, 2010, 368(1): 58-63.

[21] L. Ma, X. Guo, and L. Xiang, Catalytic activity of Ag/SBA-15 for low-temperature gas-phase selective oxidation of benzyl alcohol to benzaldehyde. Chinese Journal of Catalysis, 2014, 35(1): 108-119.

[22] P.M. Gopinath, G. Narchonai, D. Dhanasekaran, et al., Mycosynthesis, characterization and antibacterial properties of AgNPs against multidrug resistant (MDR) bacterial pathogens of female infertility cases. Asian Journal of Pharmaceutical Sciences, 2015, 10(2): 138-
145.

[23] M. I. Sriram, S.B.M. Kanth, K. Kalishwaralal, et al., Antitumor activity of silver nanoparticles in Dalton's lymphoma ascites tumor model. International Journal of Nanomedicine, 2010, 5: 753.

[24] K. Venugopal, H. Rather, K. Rajagopal, et al., Synthesis of silver nanoparticles (Ag NPs) for anticancer activities (MCF 7 breast and A549 lung cell lines) of the crude extract of Syzygium aromaticum. Journal of Photochemistry and Photobiology B: Biology, 2017, 167: 282-289.

[25] V. Dhand, L. Soumya, S. Bharadwaj, et al., Green synthesis of silver nanoparticles using Coffea arabica seed extract and its antibacterial activity. Materials Science and Engineering: C, 2016, 58: 36-43.

[26] I., Fatimah, Green synthesis of silver nanoparticles using extract of Parkia speciosa Hassk pods assisted by microwave irradiation. Journal of Advanced Research, 2016, 7(6): 961-969.

[27] M. Shivakumar, K. Nagashree, S. Yallappa, et al., Biosynthesis of silver nanoparticles using pre-hydrolysis liquor of Eucalyptus wood and its effective antimicrobial activity. Enzyme and Microbial Technology, 2017, 97: 5562.

[28] S.A. Aromal, D. Philip, Green synthesis of gold nanoparticles using Trigonella foenum-graecum and its size-dependent catalytic activity. Spectrochimica Acta Part A: Molecular and Biomolecular Spectroscopy, 2012, 97: 1-5.

[29] M.H. Matloob, A.A.A.-H. Balakita, Phenolic Content of Various Date Palms Fruits and Vinegars from Iraq. International Journal of Chemical Sciences, 2016. 14(4): 1893-1906.

[30] J. M. Andrews, Determination of minimum inhibitory concentrations. Journal of Antimicrobial Chemotherapy, 2001, 48(suppl 1): 5-16.

[31] A.R. Vilchis-Nestor, V. Sánchez-Mendieta, M.A. Camacho-López, et al., Solventless synthesis and optical properties of $\mathrm{Au}$ and $\mathrm{Ag}$ nanoparticles using Camellia sinensis extract. Materials Letters, 2008, 62(17): 31033105.

[32] V. Vidhu, S.A. Aromal, and D. Philip, Green synthesis of silver nanoparticles using Macrotyloma uniflorum. Spectrochimica Acta Part A: Molecular and Biomolecular Spectroscopy, 2011, 83(1): 392-397.

[33] G. Von White, P. Kerscher, R.M. Brown, et al., Green synthesis of robust, biocompatible silver nanoparticles using garlic extract. Journal of Nanomaterials, 2012, 2012: 55.

[34] I. Sur, D. Cam, M. Kahraman, et al., Interaction of multi-functional silver nanoparticles with living cells. Nanotechnology, 2010, 21(17): 175104.

[35] R.S. Patil, M.R. Kokate, and S.S. Kolekar, Bioinspired synthesis of highly stabilized silver nanoparticles using Ocimum tenuiflorum leaf extract and their antibacterial activity. Spectrochimica Acta Part A: Molecular and Biomolecular Spectroscopy, 2012, 91: 234-238.

[36] J. Dai, and R.J. Mumper, Plant phenolics: extraction, analysis and their antioxidant and anticancer properties. Molecules, 2010, 15(10): 7313-7352.

[37] G. Galati, P.J. O’brien, Potential toxicity of flavonoids and other dietary phenolics: significance for their chemopreventive and anticancer properties. Free Radical Biology and Medicine, 2004, 37(3): 287-303.

[38] J. Madunić, I.V. Madunić, G. Gajski, et al., Apigenin: A dietary flavonoid with diverse anticancer properties. Cancer Letters, 2018, 413: 11-22. 
[39] E. Bressan, L. Ferroni, C. Gardin, et al., Silver nanoparticles and mitochondrial interaction. International Journal of Dentistry, 2013, 2013: 312747.

[40] M. Van Gurp, N. Festjens, G. Van Loo, et al., Mitochondrial intermembrane proteins in cell death. Biochemical and Biophysical Research Communications, 2003, 304(3): 487-497.
Copyright $\subset$ Mohammed Jabber Al-Awady, Asim Alaa Balakit, Sharafaldin Al-Musawi, Mohammed Jassim Alsultani, Ahmed Kamil, and Muntadher Alabbasi. This is an open-access article distributed under the terms of the Creative Commons Attribution License, which permits unrestricted use, distribution, and reproduction in any medium, provided the original author and source are credited. 